\title{
Who bears the brunt? Distributional effects of climate change mitigation policies
}

\section{Abstract}

Climate change scholars generally urge that $\mathrm{CO}_{2}$ emissions need to be cut rapidly if we are to avoid dangerous risks of climate change. However, climate change mitigation policies are widely perceived to have regressive effects - that is, putting a higher financial burden as a proportion of household income on poor than on rich households. This is one of several major barriers to the adoption of effective mitigation policies. They would also have considerable social justice implications requiring significant welfare state responses. We assess the claim that climate change policies have regressive effects by comparing different types of mitigation policies. We will argue that many of these are indeed likely to have regressive distributional implications but that there are several policy options to counteract regressive effects.

Key words: emissions, environment, fairness, inequality, taxation

\section{Introduction}

There is long-standing interest in the distributional effects of climate change mitigation policies in the literatures on climate and energy policy, and economics. Hitherto, though, this debate has not impacted much on mainstream social policy debates (however, see Gough et al., 2008). This needs to change because climate policy will have an immediate impact on social policy through various channels, in particular 
redistribution effects. Those effects are important for two reasons. First of all, they raise questions about fairness. For instance, how do the burdens of climate change mitigation policy on citizens relate to household income? Are such burdens proportional to the impact on the environment of different lifestyles? And how can climate change policies be designed such that unjust distributional effects are avoided? Secondly, the public acceptability of such policies will influence the likelihood that governments adopt them. Little empirical research has been done in this area so far but it seems plausible that the (perceived) fairness of those policies will play an important role for public acceptability (Bristow et al., 2010). The potential power of adverse public reactions to policies is evident in the UK, for example, in the abandonment of the poll tax and more recently the fuel tax escalator. This does not necessarily imply that governments will adopt policies which are fairest and/ or most accepted by the broader public. Existing power asymmetries in society and politics mean that governments frequently respond to considerable pressure from corporate interests to adopt designs favourable to them as evidenced in relation to the European Union Emissions Trading scheme (Michaelowa and Butzengeiger, 2005). However, the fairness of climate change mitigation policies remains important from a normative point of view and their public acceptability will be one of several factors that governments take into account in the course of policy-making as, for example, DEFRA's recent research into the public acceptability of a Personal Carbon Trading scheme illustrates (DEFRA, 2008b).

This article ${ }^{1}$ analyses arguments and evidence concerning regarding the distributional impacts of a range of climate change mitigation policies. We will conclude that a range of currently debated and applied economic policy tools to mitigate climate change are likely to have regressive effects, meaning that households in lower income brackets bear a (considerably) higher burden of the cost as a percentage of their income than those in higher brackets.

However, we shall argue that the distributional effects of climate change mitigation policies will depend to a large extent on their exact design and on the area of emissions that they target (for example, emissions from home energy use as opposed to emissions from transport). As we are particularly interested in the question of how regressive effects of emissions reduction policies can be avoided for reasons that we explained above, we will compare different policy options that can be used to mitigate or at least limit those effects. 
This article focuses on 'economic instruments' rather than 'pure' regulation because they are generally regarded as more 'efficient' in the literature on climate change mitigation (see section below). However, it needs to be stressed here that so-called 'market-based' climate change mitigation policies which define an overall cap on emissions for the economy (on any scale, e.g. nationally or globally) impose a strict 'straitjacket' on the market, in effect creating a highly regulated type of market. This does not mean that there are no ethical concerns in relation to economic emission reduction instruments. One common point of contention is that economic instruments put a price on a commons 'propertizing' the earth's atmosphere. Another is that some rich people will be able to maintain their high carbon lifestyles as they are able to pay a higher price for their consumption. However, within schemes that set a strict overall cap on emissions this will not be possible for the generality of the rich. This is because the bulk of emission reductions would need to be based on a cutback of their consumption, which is currently responsible for the high emission levels of rich countries. In short, we acknowledge considerable ethical concerns about, and potential shortcomings of, market-based mitigation policies. However, we find it plausible that they form a part of any viable plan to avoid dangerous climate change, since emissions cannot be regulated away overnight.

The first section of this article provides a brief overview of different types of economic mitigation policies. The second section summarizes the findings regarding the distributional effects of different types of mitigation policies. Here we will focus on emission and energy taxes and different types of cap and trade schemes. We will also discuss the impact that different methodological choices have on study results. The third section describes the different policy options for using revenues stemming from mitigation policies, and their distributional effects. The fourth section discusses the distributional impact of mitigation policies across a wider range of socio-economic factors. The conclusion summarizes the findings and identifies points for further discussion.

\section{Types of mitigation policies}

Mitigation policies can take a variety of forms, with different advantages and disadvantages [...] from environmental, economic and distributional perspectives. Generally, one can distinguish regulation, taxes or charges, subsidies and trading schemes (Helm, 2005; OECD, 1994). 
Regulatory instruments set legally binding emission, energy use or efficiency targets which all addressees have to adhere to - or otherwise face financial and possibly penal penalties. It is frequently argued that regulation is less cost-efficient than market-based instruments because it does not reflect differing abatement costs of the various polluters. That is, it does not exploit the fact that some entities will be able to make large emissions savings at relatively low cost whilst others will find it very difficult and costly to adjust to lower emission targets.

This is one reason why economic instruments - which include various regulatory aspects - have gained prominence in the literature on environmental policy. ${ }^{2}$ These instruments essentially use price incentives and market mechanisms to generate environmentally beneficial behaviour.

The two main alternative market-based tools are carbon taxes and cap and trade schemes which both put a price on energy use or greenhouse gas emissions in order to include 'negative externalities' resulting from economic activities (e.g. pollution) in the pricing mechanism. In theory, both schemes create financial incentives to switch to lowimpact lifestyles and production methods. The key difference between the two is that environmental taxes - in economics named 'Pigovian taxes' - establish a fixed price for environmentally damaging behaviours, whereas cap and trade fixes the amount of pollution by establishing an emissions cap.

Environmental taxes are therefore believed to enhance economic security, but at the expense of environmental security, because the environmental improvement depends on actors' responses to the tax. The opposite holds true for cap and trade schemes which fix the maximum amount of pollution but let the market set the price. Consider petrol for cars, for example. Both instruments would influence the price of petrol. In the case of a tax, a fixed charge is added to the 'regular' price of every litre of petrol, whilst the additional cost under a cap and trade scheme depends on the emissions cap and the overall demand for petrol. With the cap it is certain that only the amount of petrol associated with the allowed pollution target is sold in the economy, whilst the amount of petrol sold under a fuel or carbon tax may still increase if consumers are prepared to pay a higher price.

Mitigation instruments can apply at different levels of economic activity: up-, mid- or downstream in the chain of production running from natural resource extraction down to the end user. An upstream scheme would apply a tax or emissions cap to the production or import 
of fossil fuels into the economy, thus achieving broadest coverage whilst minimizing the number of actors included in the scheme and the related administrative costs. Examples are the proposals for upstream carbon taxes (Hansen, 2009), Cap and Dividend (Barnes, 2003), Cap and Share (AEA and Cambridge Econometrics, 2008; FEASTA, 2008) or the Kyoto2 scheme (Tickell, 2008). A mid-stream scheme would apply to companies in specific economic sectors; the largest existing cap scheme, the European Union Emissions Trading Scheme (EU ETS) is an example. Downstream schemes apply to individuals, and in some variants businesses, who would have carbon accounts and trade permits themselves (DEFRA, 2008a; Fleming, 2007).

Within cap and trade schemes, several options exist as to how emission permits are allocated to the participants - all of which have different distributional impacts. Initial emission budgets can be allocated to the participants in the scheme free of charge, through auctioning, or through a mix. For example, in the European Union Emissions Trading Scheme (EU ETS), emission permits have largely been given away for free to companies in the participating sectors, depending on their previous and estimated future emissions. This approach is called 'grandfathering' in the literature. It is widely believed that this type of 'grandfathering' leads to windfall profits for companies as they can pass the additional costs on to customers or sell a considerable volume of their allocated permits. In other words, 'grandfathering' is likely to have regressive effects (Shammin and Bullard, 2009; Sijm et al., 2006). In contrast, auctioning the permits makes the polluters pay whilst the distributional effects depend on the capabilities of the targeted industries to pass on the cost to the consumer and the availability of alternatives to these goods for consumers. Furthermore, auctioning emission permits to the participants creates a revenue stream for the government or organization that issues the permits. We will discuss below how those revenues can be used to counter-balance possible regressive effects of mitigation policies.

\section{Distributional effects}

Regressivity is a general feature of taxes on consumption, and therefore one would expect carbon taxes to be regressive. This expectation also carries through to various types of cap and trade schemes. Overall, the literature on the distributional effects of mitigation policies confirms 


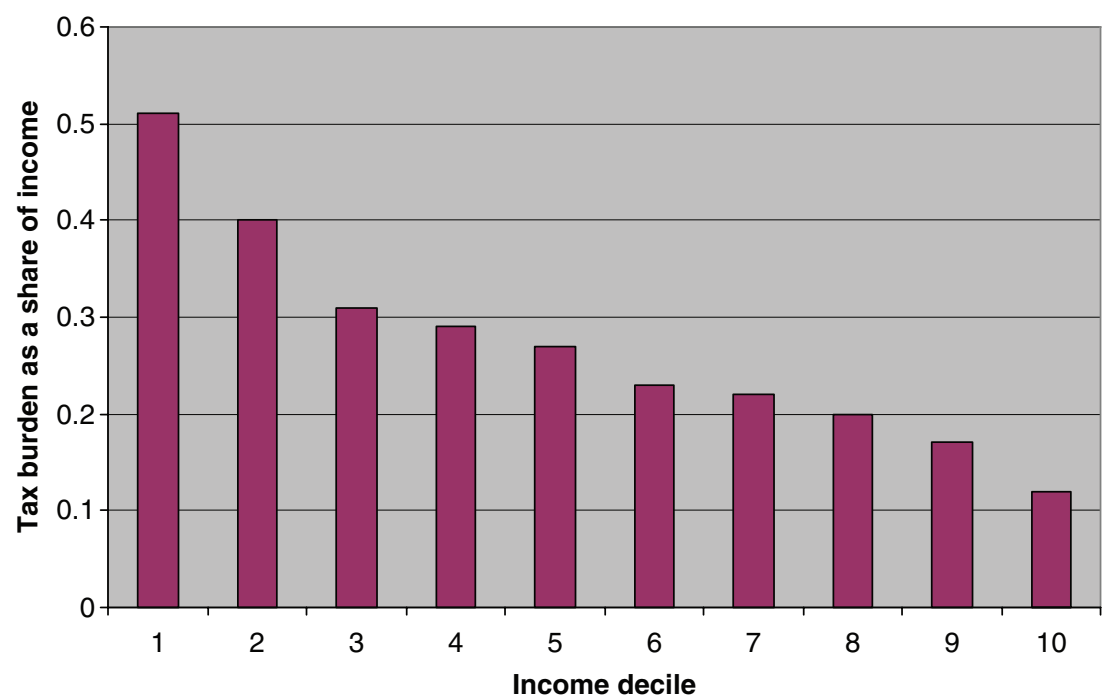

Figure 1 Estimated distributional effect of a carbon tax on home energy use of UK households

Based on Dresner and Ekins (2006: 55). In this model, the carbon tax is modelled as $0.43 \mathrm{p} / \mathrm{kWh}$ for electricity and $0.19 \mathrm{p} / \mathrm{kWh}$ for gas.

this prior view (Dresner and Ekins, 2006; Metcalf and Weisbach, 2009; Parry, 2004; Serret and Johnstone, 2006, to name but a few). However, this statement needs to be qualified as there are a range of exceptions to this rule depending on the source of pollution that is targeted, the methods applied in estimating distributional effects and, most importantly, how the revenue arising from the policy is used.

There is a general consensus that downstream taxses on home energy use are regressive if the revenue from those taxes or charges is not redistributed to the citizens (see Figure 1) (Baranzini et al., 2000; Barker and Köhler, 1998; Dresner and Ekins, 2006). The effects of such taxes, covering electricity and heating fuels, are particularly regressive because home energy use is relatively evenly distributed across income deciles (at least in industrialized countries). ${ }^{3}$ This means that low income households spend much higher shares of their income on home energy than richer households (Dresner and Ekins, 2006; Druckman and Jackson, 2008; Wier et al., 2005).

Schemes that put a price on carbon emissions further upstream, for example through a carbon tax or a cap and trade scheme that applies only to those who introduce fossil fuels into the market, have an effect 
not only on downstream energy prices but also on all other goods and services owing to the higher price of the energy used in their production. To the extent that they achieve greater emissions coverage, upstream mitigation policies are therefore likely to have additional regressive effects. For indirect emissions comprise a considerable share of households' overall emissions, in some cases more than 50\% (Druckman and Jackson, 2009: 2074; Reinders et al., 2003) whilst overall expenditure including consumer goods generally increases less than proportionally with income (see, for example, ONS, 2009, table A9, for the UK case).

However, several studies claim that upstream mitigation policies will have weaker regressive effects than downstream policies if companies that are targeted in the upstream policies are less able to pass on the price increase directly to consumers (e.g. Baranzini et al., 2000; Wier et al., 2005).

Various studies state that regressive effects of environmental taxes can be reduced or avoided if the tax is designed progressively, putting a lower burden on low income households (e.g. Baranzini et al., 2000). Frequently cited examples are the tax-free electricity allowance in the Netherlands, 1996-2001, and a progressive water charge system in Portugal (Ekins, 1999; Ekins and Barker, 2001; Wier et al., 2005). However, several authors argue that environmental policies will be more effective if distributional aspects are dealt with separately (e.g. Johnstone and Serret, 2006: 5; Metcalf and Weisbach, 2009).

The main exception to the general rule of regressivity seems to be measures to reduce emissions from transport. For example, studies that concentrate on taxes on personal transport show progressive, inequalityreducing effects if the whole population is included (Dresner and Ekins, 2004; Klinge Jacobsen et al., 2003; Tiezzi, 2005; Wier et al., 2005). The reason for this is that poorer households fly less than richer households and are less likely to own a car. However, there is also evidence that motoring taxes are regressive amongst motorists. For low income households spend a much higher share of their income on motoring fuels than high income households (e.g. Dresner and Ekins, 2004). In addition, the distributional effects of motoring taxes are influenced by the level of public transport provision within regions and countries. For example, studies using data from the United States report regressive effects of motoring taxes even if the whole population is included, because of high car dependency (Wadud et al., 2008; Walls and Hanson, 1999). 


\section{Impact of methodological choices}

The distributional effects of climate change mitigation policies presented in different studies also depend on several methodological choices, for example the type of measurement of distributional effects and whether or not behavioural responses are included in the model.

Measuring distributional effects. Studies that measure distributional effects as a share of annual disposable income tend to show greater regressive effects than studies that report shares of current expenditure, which is often used as a proxy for lifetime income (e.g. Burtraw et al., 2009; Johnstone and Serret, 2006; Klinge Jacobsen et al., 2003; Metcalf, 1999; Wier et al., 2005). This is because expenditure is more evenly distributed across households than income. ${ }^{4}$

Behavioural responses. Models estimating distributional effects of emission reduction policies can either be static or include behavioural responses. Static models simply estimate the distribution of the financial burden resulting from mitigation policies, assuming constant levels of consumption. Behavioural models also estimate the distribution of financial burdens but include estimates of changes in people's consumption behaviour in response to price increases. Those estimates are often based on 'price elasticities of demand' obtained from data on responses of consumption to price changes. The demand for goods and services is inelastic if demand does not significantly respond to prices changes - this is mostly true for 'essential' goods that cannot be replaced with cheaper equivalents, particularly for low income households. For example, Roberts et al. (1999) have argued that car use would decrease most in urban areas by low income households and be most inelastic in rural areas with poor public transport infrastructures in response to an increase in fuel duties.

Several authors argue that regressive effects of climate change mitigation policies tend to be overstated if behavioural responses are not taken into account (e.g. Johnstone and Serret, 2006; West and Williams, 2002). This can be explained by findings that high income households respond less to price changes (increases) than low income households (e.g. Brand and Boardman, 2008; Cornwell and Creedy, 1997: 599; Roberts et al., 1999: 283). If this is the case, regressive effects will appear weaker in models that include behavioural responses than those that do not. For the expenditure of low income households will be more responsive to the introduction of a carbon price than that of high income households, thereby weakening the estimated financial impact of higher prices on low income households (e.g. Labandeira 
et al., 2009; Tiezzi, 2005). However, this purely financial perspective disguises wider fairness implications as we noted in the introduction as it can be argued that poorer households will experience greater reductions in terms of their broader well-being than rich households if behavioural responses are taken into account. For example, poorer households may have to reduce spatial heating and travel and consume less whilst rich households would have the option to pay a higher price to maintain their living standards.

\section{Using the revenues from mitigation policies}

The distributional outcomes of mitigation policies also crucially depend on how the revenues are used and distributed. Revenues arise, for example, through carbon taxes or if emission permits within trading schemes are (partly) auctioned. Four options are salient in the literature, though such options could also be combined in different proportions.

1) If the revenue from mitigation policies is not earmarked for direct redistribution to citizens, those policies are highly likely to have regressive effects as shown above, perhaps with the exception of schemes that only include transport emissions.

2) Governments can earmark the revenue from mitigation policies to finance measures that further reduce greenhouse gas emissions or support behavioural adaptation. For example energy efficiency measures such as home insulation programmes, investments into renewable energy or public transport subsidies, training, and research and development can be supported.

The distributional effects depend on who is benefiting from those programmes. For example, means-tested home insulation programmes like the Warm Front programme in the UK benefit low income households, and subsidies for public transport currently primarily benefit low income urban households. Policies that aim to expand renewable energy, in contrast, can have regressive effects if they work through financial incentives to (already wealthy) homeowners. This has been a controversial aspect of feed-in tariffs for solar electricity (Monbiot 2010).

3) The revenue from taxes or auctions under cap and trade schemes can be fully redistributed to the population and/or industry. There are several options for doing this, which have different distributional consequences. The first option is frequently discussed in the 
environmental economics literature in relation to the 'double dividend' hypothesis of 'green taxes'. That is, scholars typically argue that the tax creates incentives to reduce the activities that give rise to 'negative externalities' such as pollution, and that the revenue generated can be 'recycled' for any other purpose, including the reduction of taxes on income or capital. If we return to our example on petrol, not only would the tax set an incentive for customers to buy less petrol, but the raised revenue could be used to offset other tax burdens, for example income tax. From a mainstream economics perspective, this would limit market distortions that those taxes might imply, for example reduced work incentives. If the entire revenue is earmarked to decrease/remove other taxes, the tax reform is termed 'revenue neutral', meaning that the costs of the new source of revenue are completely compensated through the reduction of other taxes or charges.

Studies on the effects of reducing social security contributions, taxes on income, or VAT so far show mixed results. A study on the German 'eco tax' demonstrated that the reduction of the contribution to pension insurance actually increased the regressive effect as the reduction mainly benefited middle income households but disadvantaged low income, unemployed and pensioner households (Bach et al., 2002; Bork, 2006).

A reduction of income tax can be designed in a progressive way which decreases taxes on low incomes more than on higher incomes. It therefore has tended to have progressive effects in practice according to a range of studies (e.g. Grainger and Kolstad, 2008; Metcalf, 1999; Metcalf and Weisbach, 2009) (an exception is Burtraw et al., 2009). Labandeira et al.'s (2009) study of a revenue-neutral reduction of VAT as a compensating mechanism also showed progressive effects. The second option is for the revenue to be returned to citizens by increasing specific social security benefits, for example child benefit or meanstested benefits such as tax credits or income support. With this option, regressive effects can be considerably reduced or even reversed as several studies have demonstrated (Baranzini et al., 2000; Dresner and Ekins, 2006; Ekins and Barker, 2001; Ekins and Dresner, 2004).

4) A final option is to return the revenue from mitigation policies directly to individuals or households as a lump sum. There is a substantial literature discussing this option (Barker and Köhler, 1998; CEC, 1992; Dinan and Rogers, 2002; Ekins and Barker, 2001; Parry, 2004; West and Williams, 2002). In the United States, a 'carbon tax and $100 \%$ dividend' proposal has recently been promoted by climate 
scientist James Hansen (2009). An equal per capita rebate or free allocation of emission permits (which is distributionally equivalent) is also integral to Personal Carbon Trading (PCT) (DEFRA, 2008a), Cap and Share and Cap and Dividend schemes (Barnes, 2003; FEASTA, 2008). Under PCT, individuals receive equal per capita tradable carbon allowances. Under Cap and Dividend, an independent climate trust would auction off the permits to upstream fossil fuel producers or importers and redistribute equal per capita rebates to the citizens. Under Cap and Share, an independent trust would allocate each citizen with an equal share of the nation's emission permits which they can then sell via banks or post offices. Fossil fuel producers or importers would have to buy the permits to cover the carbon content of the products that they intend to sell on the market.

Studies that examined the distributional effects of equal per capita rebates usually conclude that this option has strongly progressive effects on average (AEA and Cambridge Econometrics, 2008; Barker and Köhler, 1998; DEFRA, 2008a; Dinan and Rogers, 2002; Parry, 2004; Starkey and Anderson, 2005). This means that low income households will gain more (lose less) as a share of their income than high income households. For example, in a Cap and Share or Cap and Dividend scheme, any individual who consumes less than the capped level of emissions will financially gain from the rebate/revenue (AEA and Cambridge Econometrics, 2008; Boyce and Riddle, 2007). As low income households usually generate relatively low emissions, they may gain from the scheme. Even if gains were equal across the income distribution, it would be larger as a share of income for poorer than for richer households. If poorer households gain more in absolute terms than richer households, the distributional effect will be strongly progressive in relative terms. However, as we will see in the following section, those findings are complicated by a range of additional socioeconomic characteristics and dynamic considerations.

The distributional effects of lump-sum rebate schemes also depend on the level of the cap. PCT or Cap and Share/Dividend schemes will be progressive as long as low income households generally consume less than their initial allocation of emissions/energy. If a scheme applies internationally with the same per capita allocation across the whole scheme, its distributional effects are likely to be regressive in highly developed countries. For example, a global scheme that allocated a budget of 4 tonnes of $\mathrm{CO}_{2}$ per year to each citizen in 2006, slightly below the then world average of 4.39 tonnes of $\mathrm{CO}_{2}$ per person, would 
have regressive effects in most industrialized countries as their average per capita emissions are much higher (in the UK, annual per capita emissions were 9.37 tonnes $\mathrm{CO}_{2}$, in the US 19 tonnes $\mathrm{CO}_{2}$ in 2006). ${ }^{5}$ However, those schemes would be extremely progressive in less developed countries. See Wakeford (2008) and Sharan (2008) on the impact of a Cap and Share scheme on South Africa and India respectively.

\section{Socio-demographic factors}

The previous section was confined to a consideration of the distributional effects of mitigation policies across income bands. Whilst this is a key dimension of distributional effects, there are a range of additional socio-economic characteristics which are important. The burdens (and benefits) of mitigation policies are unequally distributed across dimensions such as household size, type of dwelling, urban/rural location and so on. An analysis of distributional effects that only focuses on income groups disguises considerable variations of the distribution of burdens and benefits within income groups, because of such additional factors. Various studies confirm this insight. For example, Dresner and Ekins (2006: 52) report that the correlation between income and emissions is actually relatively low (see also Cohen et al., 2005; Hills, 2009; Vringer and Blok, 1995). Several studies also report that even with full and equal per capita revenue recycling, that is an equal per capita payment to all citizens financed through the revenue from the emissions reduction policy, a substantial proportion of low income households would still lose out under such a scheme (DEFRA, 2008a: 3; Dresner and Ekins, 2004: 4; 2006: 55). Estimates of this proportion range up to $30 \% .^{6}$ An analysis of the role of a wider range of socio-economic characteristics is therefore important to uncover and understand the variation of distributional effects within income groups. Those variations are linked to issues of fairness which have to be taken into account by policy-makers.

Several mitigation studies examine such characteristics (e.g. DEFRA, 2008a; Dresner and Ekins, 2006; Klinge Jacobsen et al., 2003; Labandeira et al., 2009; Tiezzi, 2005; Wier et al., 2005). A consistent (if predictable) finding is that, in addition to income or expenditure, household size is very important: the larger the number of household members the higher the emissions. However, if emissions are measured per capita, emissions decrease with household size owing to economies 
of scale (e.g. Baiocchi et al., 2010; DEFRA, 2008a; Wier et al., 2005). The trend towards smaller household sizes is therefore a driving factor behind increasing per capita emissions in many rich countries, particularly if indirect emissions are included (Druckman and Jackson, 2008: 3184).

Most studies also conclude that the type of dwelling has a key effect on household emissions. The more 'separated' and less insulated a dwelling is, the more energy is required for heating. Large, detached bungalows are therefore on average the dwelling with highest emissions whilst emissions on average decrease across detached, semidetached, terraced houses and flats (DEFRA, 2008a; Druckman and Jackson, 2008).

Other socio-economic factors are also significant but the literature is less conclusive regarding their overall effects. Consider location, for example. Whilst rural households have on average higher emissions (and therefore higher burdens from mitigation policies), there are different possible reasons for this. DEFRA (2008a: 4) claims, for example, that less access to mains gas (which has lower emissions per energy unit than any other fossil fuel) and less well insulated houses in rural areas are the main reasons for higher rural emissions, rather than greater dependency on cars. Whilst it is unclear whether higher rural emissions are also partly driven by higher incomes, it is obvious that low income households residing in rural areas are likely to bear higher than average burdens from mitigation policies even if the revenues are recycled to low income households.

Some studies also find effects for the age of the household representative $^{7}$ person and their employment status. Here, most studies report that households in which the representative is aged 30-65 have higher emissions than households in which they are younger or older. Households with 'economically inactive's representatives (for example lone parents, unemployed people or pensioners) are also generally estimated to have low emissions (Brand and Preston, 2010; Druckman and Jackson, 2008).

This reflects the fact that people in those groups are disproportionately affected by poverty, resulting in low levels of consumption. However, some studies stated that from home energy use, pensioner households have comparatively high emissions as pensioners often live in large family homes ('over-occupation'), spend a large share of the day at home with their heating switched on and generally have higher warmth requirements than average households (e.g. Baiocchi et al., 2010; DEFRA, 2008a; Tindale and Hewett, 1999). 
So far, relatively few studies use multivariate regression analysis to examine the relative impact of different socio-economic factors (Baiocchi et al., 2010; Brand and Preston, 2010; DEFRA, 2008a; Lenzen et al., 2006; Weber and Matthews, 2008). A comparison of those studies demonstrates some similarities but also considerable differences depending on the model (independent and dependent variables, type of regression model) and country. Three studies examining the relative impact of different variables on household energy requirements (Lenzen et al., 2006: 192) or $\mathrm{CO}_{2}$ emissions (Baiocchi et al., 2010: 63; Weber and Matthews, 2008: 384) found that expenditure or income was the most significant variable with positive effects on the dependent variable. Lenzen et al. (2006: 192) and Baiocchi et al. (2010: 63) also found that age had a positive significant effect. However, income had a less significant impact on household emissions than the number of adults, number of vehicles or central heating type in DEFRA's study (2008a: 31 , demonstrating again that distributional effects can vary considerably within income brackets and that additional policies might be required to tackle those unequal effects.

An interesting contrast appears in Brand and Preston's (2010: 17) study on individual emissions from personal travel. In their study, pension age had a highly negative effect on emissions. Low income was still significant with a negative effect whilst high income was not significant at the 0.05 level, compared to middle income households.

\section{Conclusions}

The literature exhibits a broad consensus that climate change mitigation policies usually have regressive effects in the absence of compensatory revenue recycling. However, it also suggests that exceptions exist to this rule. Policies that target personal transport are usually progressive. Study results are often influenced by the choice of country as climatic conditions, energy efficiency of the housing stock, level of car-ownership, public transport infrastructure, levels of poverty and income inequality and so on all make a difference to potential distributional effects. Study results also depend on methodological choices, such as the measure that is used to examine distributional effects and whether or not behavioural responses are included in the model. 
The most effective measures to counteract regressive outcomes seem to be lump-sum revenue recycling schemes. However, there are several issues related to this which require further debate and research:

i. The literature indicates that, for a variety of reasons, there will still be a substantial proportion of lower income losers owing to high direct or indirect fossil fuel energy use under lump-sum recycling arrangements. Further research is required to identify the characteristics of low income groups at risk of losing out under lump-sum recycling arrangements. ${ }^{9}$

ii Further compensatory policy options may be required to help households making a transition to low-impact lifestyles, including home insulation, microgeneration as well as public transport programmes. However, additional research is required to examine the distributional effects of these programmes.

iii. Whilst lump-sum rebates are likely to attract wide public support, they are likely to be opposed by (high emitting) wealthier people and businesses. In addition, in times of financial austerity, governments may be keen to use revenues from mitigation policies for purposes other than compensating low income households. ${ }^{10}$ The barriers emerging from power asymmetries as well as economic and political contexts to adopting effective mitigation policies need to be further investigated.

iv. Public support for lump-sum recycling climate change mitigation schemes is likely to disappear completely in rich countries such as the UK if such schemes are introduced at an international scale and if the annual per capita allowance is lower than the annual emission tonnage of even the lowest income households. This is because international equal allowance and lump-sum rebate schemes would be regressive in rich countries, and trigger an enormous transfer of resources from the developed to the less developed world. Policy options of mitigating those effects need to be further investigated. One possibility could be the application of 'contraction and convergence' (Meyer, 2000) frameworks which envisage equal per capita allowances at a later point in time, thus implying less immediate redistributions between rich and poor nations.

v. Finally, a key issue which so far appears to have been relatively neglected in the literature on distributional effects is the dynamic aspect of the climate change mitigation challenge. Politicians have tended to focus on emissions reduction targets of the form ' $\mathrm{x} \%$ by year $\mathrm{Y}$ ', such as the UK's 
current $80 \%$ emissions reduction by 2050 target. Climate researchers have in contrast called for finite greenhouse gas budgets, implying a steep trajectory for emissions reductions, and thus net-emissions ${ }^{11}$ budgets that reduce rapidly year on year until they approach zero (Anderson and Bows, 2008). Of course, revenue can only arise from carbon reduction policies as long as there are emissions left that can be reduced - once net-emissions have reached zero, the revenue stream from those policies will run dry. Thus, any dividend from mitigation policy would have to be seen as a temporary palliative aiding the shift to a transformed, zero net-emissions economy, rather than as a permanent resource of social policy. A research issue arising here is whether measures to mitigate regressivity will ultimately, therefore, be more effective if they provide benefits in kind, helping people to make practical transitions towards a low carbon future, rather than income alone.

\section{Acknowledgements}

The authors would like to thank the participants of the stream 'Financing the Welfare State' at the 2009 ESPAnet conference, Urbino, Italy, the editor Rachel Aldred and an anonymous reviewer for helpful comments on previous versions of this paper.

\section{Notes}

1. The article is based on an extensive review of the literature published between the late 1990s and April 2010, including 53 journal articles, book chapters, working papers and government agency reports published in English. Of the 53 articles covered in this article, 6 examined the UK, 30 analysed other OECD countries (primarily the USA), 4 focussed on non-OECD countries, 9 compared several countries and 4 focussed based on theoretical models. Owing to space constraints we cannot include citations to all the literature we reviewed.

2. This may also be related to the general dissatisfaction amongst policymakers with central planning following the economic demise of the Soviet bloc in the 1990s.

3. Klinge Jacobsen et al. (2003: 494) argue that electricity and water can be 'luxury goods' in developing countries with lower income groups consuming much less of those goods than higher income groups. This is likely to make electricity and water taxation progressive in those countries. 
4. It should be noted here that distributional effects of mitigation policies are sometimes also assessed using Lorenz curves, the Gini coefficient or other measures of distributive inequality. Those studies compare the degree of income inequality before and after a mitigation policy had been introduced. An increase in income inequality means that a mitigation policy has regressive effects and vice versa (e.g. Barros and PrietoRodriguez, 2008; Klinge Jacobsen et al., 2003).

5. These are the latest available data. Source: World Bank Development Indicators, available at http://data.worldbank.org/topic/environment

6. However, studies on the distribution of emissions usually rely on expenditure surveys. The quality of those surveys is usually affected by the 'infrequency of purchase' problem as they only cover brief expenditure periods of individual households. Whilst over- or under-estimation of expenditure is likely to even out within large datasets, the dispersion around the mean will be biased. This also applies to individual income deciles. Hence, estimates regarding the proportion of low income people who stand to lose or win from a policy package need to be treated with caution.

7. Most of those studies are based on household income or other measures mainly because of lack of data at the individual level. Estimating distributional effects at the household level is naturally limited as it does not take different levels of individual emissions and related distributional effects of mitigation policies within households into account. For example, it would be interesting to investigate gender differences within households. Studies that are based on single households suggest that men eat more meat and drive longer distances than women and may therefore be responsible for a larger proportion of household emissions than women (Räty and Carlsson-Kanyama, 2010).

8. The statistical classification of 'economically inactive' of course neglects the unpaid work with which people in this category contribute to the economy, particularly the unpaid and therefore marginalized care-work by lone parents and other carers.

9. This is a question that we, Milena Büchs, Sylke Schnepf and Nicholas Bardsley, will address in our project on 'Who emits most? An analysis of UK households' $\mathrm{CO}_{2}$ emissions and their association with socioeconomic factors' (ESRC RES-000-22-4083) starting in May 2011.

10. Such mistrust in government has led several advocacy organizations to propose delegation of decisions on emission reduction targets as well as redistribution of lump sums to an independent trust (e.g. Barnes, 2003; FEASTA, 2008).

11. Any residual carbon emissions occurring in such an economy would need to be counter-balanced through carbon sequestration or capture which remove equivalent amounts of carbon from the atmosphere. 


\section{References}

AEA and Cambridge Econometrics (2008) 'A Study in Personal Carbon Allocation: Cap and Share', a report to Comhar SDC Sustainable Development Council, Ireland. AEA Energy \& Environment and Cambridge Econometrics. [http://www.feasta.org/documents/energy/Comhar_Cap_ and_Share_Report.pdf], accessed 19 January 2009.

Anderson, K. and Bows, A. (2008) 'Reframing the Climate Change Challenge in Light of Post-2000 Emission Trends', Philosophical Transactions of the Royal Society A: Mathematical, Physical and Engineering Sciences 366(1882): 3863-82.

Bach, S., Kohlhaas, M., Meyer, B., Praetorius, B. and Welsch, H. (2002) 'The Effects of Environmental Fiscal Reform in Germany: A Simulation Study', Energy Policy 30(9): 803-11.

Baiocchi, G., Minx, J. and Hubacek, K. (2010) 'The Impact of Social Factors and Consumer Behavior on Carbon Dioxide Emissions in the United Kingdom', Journal of Industrial Ecology 14(1): 50-72.

Baranzini, A., Goldemberg, J. and Speck, S. (2000) 'A Future for Carbon Taxes', Ecological Economics 32(3): 395-412.

Barker, T. and Köhler, J. (1998) 'Equity and Ecotax Reform in the EU: Achieving a 10 Per Cent Reduction in $\mathrm{CO}_{2}$ Emissions Using Excise Duties', Fiscal Studies 19(4): 375-402.

Barnes, P. (2003) Who Owns the Sky? Our Common Assets and the Future of Capitalism. Washington DC: Island Press.

Barros, C. P. and Prieto-Rodriguez, J. (2008) 'A Revenue-Neutral Tax Reform to Increase Demand for Public Transport Services', Transportation Research Part A: Policy and Practice 42(4): 659-72.

Bork, C. (2006) 'Distributional Effects of the Ecological Tax Reform in Germany: An Evaluation with a Microsimulation Model', pp. 139-70 in Y. Serret and N. Johnstone (eds) The Distributional Effects of Environmental Policy. Cheltenham: Edward Elgar / OECD.

Boyce, J. and Riddle, M. (2007) 'Cap and Dividend: How to Curb Global Warming While Protecting the Incomes of American Families', Working Paper Series Number 150. Amherst: Political Economy Research Institute, University of Massachusetts.

Brand, C. and Boardman, B. (2008) 'Taming of the Few: The Unequal Distribution of Greenhouse Gas Emissions from Personal Travel in the UK', Energy Policy 36(1): 224-38.

Brand, C. and Preston, J. M. (2010) ““60-20 Emission”: The Unequal Distribution of Greenhouse Gas Emissions from Personal, Non-business Travel in the UK', Transport Policy 17(1): 9-19.

Bristow, A. L., Wardman, M., Zanni, A. M. and Chintakayala, P. K. (2010) 'Public Acceptability of Personal Carbon Trading and Carbon Tax', Ecological Economics 69(9): 1824-37. 
Burtraw, D., Sweeney, R. and Walls, M. (2009) 'The Incidence of U.S. Climate Policy: Alternative Uses of Revenues from a Cap-and-Trade Auction', National Tax Journal 62: 497-518.

CEC (1992) 'European Economy: The Climate Challenge - Economic Aspects of the Community's Strategy for Limiting $\mathrm{CO}_{2}$ Emissions', European Economy 51, Commission of the European Communities. Luxembourg: Office for Official Publications.

Cohen, C., Lenzen, M. and Schaeffer, R. (2005) 'Energy Requirements of Households in Brazil', Energy Policy 33(4): 555-62.

Cornwell, A. and Creedy, J. (1997) 'Measuring the Welfare Effects of Tax Changes Using the LES: An Application to a Carbon Tax', Empirical Economics 22(4): 589-613.

DEFRA (2008a) 'Distributional Impacts of Personal Carbon Trading'. March. London: Department for Environment, Food and Rural Affairs. [http:// www.defra.gov.uk/environment/climatechange/uk/individual/carbontrading/pdf/pct-distributional-impacts.pdf\}, accessed 1 July 2008.

DEFRA (2008b) 'Personal Carbon Trading: Public Acceptability', March. London: Department for Environment, Food and Rural Affairs.

Dinan, T. and Rogers, D. L. (2002) 'Distributional Effects of Carbon Allowance Trading: How Government Decisions Determine Winners and Losers', National Tax Journal 55(2): 199-221.

Dresner, S. and Ekins, P. (2004) 'The Distributional Impacts of Economic Instruments to Limit Greenhouse Gas Emissions from Transport', PSI Research Discussion Paper 19. London: Policy Studies Institute.

Dresner, S. and Ekins, P. (2006) 'Economic Instruments to Improve UK Home Energy Efficiency without Negative Social Impacts', Fiscal Studies 27(1): 47-74.

Druckman, A. and Jackson, T. (2008) 'Household Energy Consumption in the UK: A Highly Geographically and Socio-economically Disaggregated Model', Energy Policy 36(8): 3177-92.

Druckman, A. and Jackson, T. (2009) 'The Carbon Footprint of UK Households 1990-2004: A Socio-economically Disaggregated, Quasi-MultiRegional Input-Output Model', Ecological Economics 68(7): 2066-77.

Ekins, P. (1999) 'European Environmental Taxes and Charges: Recent Experience, Issues and Trends', Ecological Economics 31: 39-62.

Ekins, P. and Barker, T. (2001) 'Carbon Taxes and Carbon Emissions Trading', Journal of Economic Surveys 15(3): 325-76.

Ekins, P. and Dresner, S. (2004) 'Green Taxes and Charges: Reducing their Impact on Low-income Households'. York: Joseph Rowntree Foundation. [http://www.jrf.org.uk/sites/files/jrf/1859352472.pdf], accessed 18 March 2009.

FEASTA (2008) 'Cap \& Share: A Fair Way to Cut Greenhouse Emissions'. Dublin: The Foundation for the Economics of Sustainability (FEASTA). 
[http://www.feasta.org/documents/energy/Cap-and-Share-May08.pdf], accessed 4 July 2008.

Fleming, D. (2007) 'Energy and the Common Purpose: Descending the Energy Staircase with Tradable Energy Quotas (TEQs)'. London: The Lean Economy Connection.

Gough, I., Meadowcroft, J., Dryzek, J., Gerhards, J., Lengfeld, H., Markandya, A. and Ortiz, R. (2008) 'JESP Symposium: Climate Change and Social Policy', Journal of European Social Policy 18(4): 325-44.

Grainger, C. and Kolstad, C. (2008) 'Who Pays for a Carbon Tax?', University of California (conference paper). [http://stanford.edu/dept/francestanford/Conferences/Climate/Kolstad.pdf], accessed 30 March 2009.

Hansen, J. E. (2009) 'Carbon Tax \& 100\% Dividend'. Testimony of James E. Hansen to Committee on Ways and Means, United States House of Representatives, 25 February. [http://www.columbia.edu/ jeh1/2009/ WaysAndMeans_20090225.pdf], accessed 22 July 2009.

Helm, D. (2005) Climate-Change Policy. Oxford: Oxford University Press.

Hills, J. (2009) 'Future Pressures: Intergenerational Links, Wealth, Demography and Sustainability', pp. 319-40 in J. Hills, T. Sefton and K. Stewart (eds) Towards a More Equal Society? Poverty, Inequality and Policy since 1997. Bristol: Policy Press.

Johnstone, N. and Serret, Y. (2006) 'Distributional Effects of Environmental Policy: Introduction', pp. 1-19 in Y. Serret and N. Johnstone (eds) The Distributional Effects of Environmental Policy. Cheltenham: Edward Elgar / OECD.

Klinge Jacobsen, H., Birr-Pedersen, K. and Wier, M. (2003) 'Distributional Implication of Environmental Taxation in Denmark', Fiscal Studies 24(4): 477-99.

Labandeira, X., Labeaga, J. M. and Rodriguez, M. (2009) 'An Integrated Economic and Distributional Analysis of Energy Policies', Energy Policy 37(12): 5776-86.

Lenzen, M., Wier, M., Cohen, C., Hayami, H., Pachauri, S. and Schaeffer, R. (2006) 'A Comparative Multivariate Analysis of Household Energy Requirements in Australia, Brazil, Denmark, India and Japan', Energy 31(2-3): 181-207.

Metcalf, G. E. (1999) 'A Distributional Analysis of Green Tax Reforms', National Tax Journal 52(4): 655-81.

Metcalf, G. E. and Weisbach, D. (2009) 'The Design of a Carbon Tax', Harvard Environmental Law Review 33(2): 499-556.

Meyer, A. (2000) Contraction and Convergence: The Global Solution to Climate Change. Totnes: Green Books.

Michaelowa, A. and Butzengeiger, S. (2005) 'EU Emissions Trading: Navigating between Scylla and Charybdis', Climate Policy 5(1): 1-9.

Monbiot, G. (2010) 'Are We Really Going to Let Ourselves Be Duped into this Solar Panel Rip-off?', The Guardian 1 March. 
OECD (1994) Managing the Environment: The Role of Economic Instruments. Paris: Organisation for Economic Co-Operation and Development (OECD).

ONS (Office for National Statistics) (2009) Family Spending: A Report on the 2008 Living Costs and Food Survey. Basingstoke: Palgrave Macmillan.

Parry, I. W. H. (2004) 'Are Emissions Permits Regressive?', Journal of Environmental Economics and Management 47(2): 364-87.

Räty, R. and Carlsson-Kanyama, A. (2010) 'Energy Consumption by Gender in Some European Countries', Energy Policy 38(1): 646-9.

Reinders, A. H. M. E., Vringer, K. and Blok, K. (2003) 'The Direct and Indirect Energy Requirement of Households in the European Union', Energy Policy 31(2): 139-53.

Roberts, D., Farrington, J., Gray, D. and Martin, S. (1999) 'The Distributional Effects of Fuel Duties: The Impact on Rural Households in Scotland', Regional Studies 33(3): 281-8.

Serret, Y. and Johnstone, N. (2006) The Distributional Effects of Environmental Policy. Cheltenham: Edward Elgar/ OECD.

Shammin, M. R. and Bullard, C. W. (2009) 'Impact of Cap-and-Trade Policies for Reducing Greenhouse Gas Emissions on US Households', Ecological Economics 68(8-9): 2432-8.

Sharan, A. (2008) 'Potential Impacts of a Global Cap and Share Scheme on India'. Dublin: FEASTA. [http://www.capandshare.org/download_files/ C\&S_India_report.pdf], accessed 23 March 2009.

Sijm, J., Neuhoff, K. and Chen, Y. (2006) 'CO Cost Pass-Through and Windfall Profits in the Power Sector', Climate Policy 6(1): 49-72.

Starkey, R. and Anderson, K. (2005) 'Domestic Tradable Quotas: A Policy Instrument for Reducing Greenhouse Gas Emissions from Energy Use'. Technical Report 39. Norwich: Tyndall Centre for Climate Change Research.

Tickell, O. (2008) Kyoto2: How to Manage the Global Greenhouse. London: Zed Books.

Tiezzi, S. (2005) 'The Welfare Effects and the Distributive Impact of Carbon Taxation on Italian Households', Energy Policy 33(12): 1597-612.

Tindale, S. and Hewett, C. (1999) 'Must the Poor Pay More? Sustainable Development, Social Justice, and Environmental Taxation', pp. 233-48 in A. Dobson (ed.) Fairness and Futurity: Essays on Environmental Sustainability and Social Justice. Oxford: Oxford University Press.

Vringer, K. and Blok, K. (1995) 'The Direct and Indirect Energy Requirements of Households in the Netherlands', Energy Policy 23(10): 893-910.

Wadud, Z., Noland, R. B. and Graham, D. J. (2008) 'Equity Analysis of Personal Tradable Carbon Permits for the Road Transport Sector', Environmental Science E Policy 11(6): 533-44. 
Wakeford, J. (2008) 'Potential Impacts of a Global Cap and Share Scheme on South Africa'. Dublin: FEASTA. [http://www.capandshare.org/download_files/C\&S_South_Africa_report.pdf\}, accessed 23 March 2009.

Walls, M. and Hanson, J. (1999) 'Distributional Aspects of an Environmental Tax Shift: The Case of Motor Vehicle Emissions Taxes', National Tax Journal 52(1): 53-65.

Weber, C. L. and Matthews, H. S. (2008) 'Quantifying the Global and Distributional Aspects of American Household Carbon Footprint', Ecological Economics 66(2-3): 379-91.

West, S. E. and Williams, R. C. (2002) 'Estimates from a Consumer Demand System: Implications for the Incidence of Environmental Taxes', Working Paper 9152. Cambridge, MA: National Bureau of Economic Research. [http://www.macalester.edu/ wests/NBER9152.pdf]

Wier, M., Birr-Pedersen, K., Jacobsen, H. K. and Klok, J. (2005) 'Are $\mathrm{CO}_{2}$ Taxes Regressive? Evidence from the Danish Experience', Ecological Economics 52(2): 239-51.

- Milena Büchs is lecturer in sociology and social policy at the University of Southampton. Her current research focuses on household $\mathrm{CO}_{2}$ emissions and inequality (ESRC) and the role of third sector organizations in promoting low carbon practices (ESRC-funded Third Sector Research Centre). She has previously worked and published on European Union social policy and social policy governance, including 'How legitimate is the Open Method of Coordination?', Journal of Common Market Studies, 2008, 46(4): 765-86; 'The Open Method of Coordination: Effectively preventing welfare state retrenchment?', European Integration online Papers (EIoP), 2009, Vol. 13. Address: School of Social Sciences, Sociology and Social Policy, University of Southampton, Highfield, Southampton SO17 1BJ, UK.email: m.buechs@ soton.ac.uk

- Nicholas Bardsley is lecturer in climate change economics at the School of Agriculture, Policy and Development, University of Reading. His current research focuses on household $\mathrm{CO}_{2}$ emissions and inequality (ESRC), and household energy use (ESRC / EPSRC). He also has a long-standing interest in behavioural economics. His recent publications include (with R. Cubitt, G. Loomes, P. Moffatt, C. Starmer and R. Sugden), Experimental Economics: Rethinking the Rules (Princeton University Press, 2010). 
- Sebastian Duwe is a doctoral student associated with the Environmental Policy Research Centre (FFU) at the Free University Berlin. His research focuses on the governance of the transition to low carbon economies. He holds a Bachelor in Political Science from the Free University Berlin and a Master of Public Policy degree from the Hertie School of Governance. Besides his studies, he works as a freelance consultant for various agencies including the German Federal Ministry of Health. 